\title{
Spontaneous Fracture of a Biliary Self-Expanding Metal Stent
}

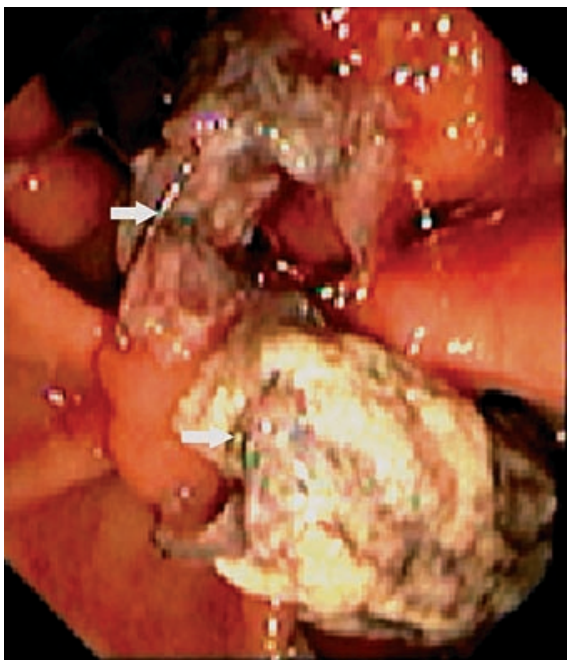

Figure 1 Endoscopic view of the fractured self-expanding metal stent (SEMS), which was clogged with debris (bottom arrow). It had migrated distally and appeared to be fragmented, with the proximal end of the distal segment anchored to the ampulla by a single strand (top arrow).

The endoscopic placement of a self-expanding metallic stent (SEMS) is an established treatment for inoperable malignant biliary obstruction, providing relatively prolonged palliation with acceptably low failure and complication rates [1]. Complications related to SEMSs include entrapment of the stent delivery system in small or nondilated intrahepatic ducts, malpositioning of the stent, stent occlusion due to tumor ingrowth or biliary epithelial hyperplasia, proximal or distal migration, and trauma to the duodenal wall opposite the papilla, resulting in bleeding or perforation. Although SEMS are generally not removable, successful endoscopic retrieval of such stents for the treatment of late complications has been reported. Fracture of a SEMS is a rare complication and has only occasionally been reported in the biliary system, caused by thermal overstrain during the application of laser or electrocautery [2-5].

A 63-year-old woman with distal cholangiocarcinoma, who had undergone placement of a Za-stent (Wilson-Cook Medical

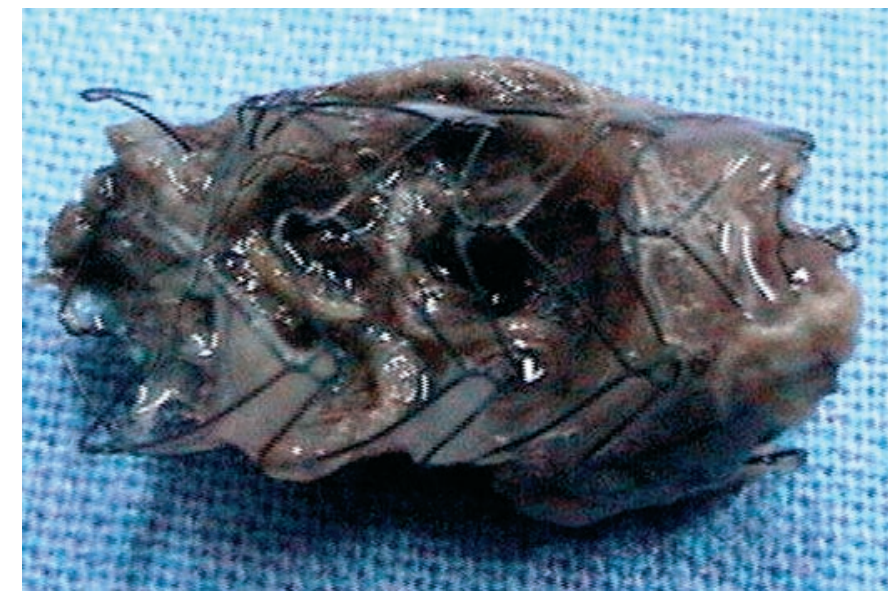

Figure 2 The distal fragment of the SEMS, which was retrieved with a rat-tooth forceps.

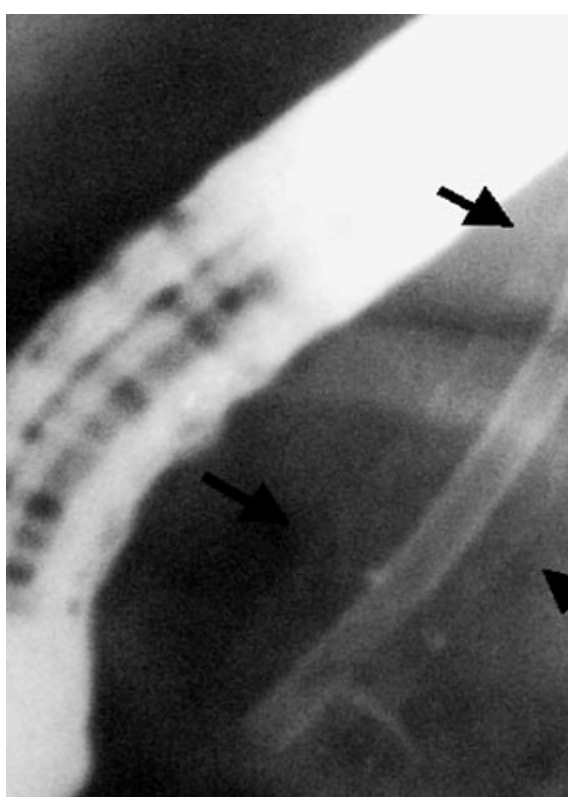

Figure 3 A 10-Fr Cotton-Leung plastic stent was inserted through the intrabiliary portion of the clogged proximal fragment of the metallic stent.

Inc., Winston-Salem, North Carolina, USA) 6 months previously, presented with cholangitis. On duodenoscopy, the stent was found to be clogged with debris. It had migrated distally, and it appeared to be fragmented, with the proximal end of the distal segment anchored to the ampulla by a single strand (Figure $\mathbf{1}$ ). This firmly embedded wire was carefully de- tached and the distal fragment was retrieved with a rat-tooth forceps (WilsonCook Medical) under fluoroscopic control (Figure 2). A 10-Fr Cotton-Leung biliary plastic stent (Wilson-Cook Medical) was then inserted through the remaining intrabiliary portion of the clogged proximal fragment of the metallic stent (Figure $\mathbf{3}$ ).

To the best of our knowledge, spontaneous fracture of an endoscopically placed biliary SEMS has not been previously reported. In the patient presented here, we describe the first case of a spontaneous fracture of a Za-stent, 6 months after insertion. This stent is constructed of round shape-retaining nickel-titanium (nitinol) wire to provide superior flexibility and shape retention without shortening, while minimizing the risk of tissue damage. In this case, it is conceivable that the malignant stricture was too soft to retain the stent in position, leading to distal migration into the duodenal lumen at an acute angle. This would have exposed the stent to the shearing forces exerted by duodenal peristalsis, resulting in stress fracture and eventual separation of the fragments. However, the possibility of bile-induced corrosion of the stent cannot be completely ruled out. 
P. V. J. Sriram¹, A. Ramakrishnan², G. V. Rao' ${ }^{1}$, D. Nageshwar Reddy ${ }^{1}$

${ }^{1}$ Departments of Gastroenterology and Minimally Invasive Surgery, Asian Institute of Gastroenterology, Hyderabad, India

${ }^{2}$ Graduate Hospital, MCP/Hahnemann University, Philadelphia, USA.

\section{References}

${ }^{1}$ Sung JJY, Chung SCS. Endoscopic stenting for palliation of malignant biliary obstruction: a review of progress in the last 15 years. Dig Dis Sci 1995; 40: 1167-1173

${ }^{2}$ Ell C, Fleig WE, Hochberger J. Broken biliary metal stent after repeated electrocoagulation for tumor in-growth. Gastrointest Endosc 1992; 38: 197- 199
${ }^{3}$ Mallat A, Saint-Marc GirardinMF, Meduri Bet al. Fracture of biliary endoprosthesis after endoscopic drainage for malignant biliary obstruction: report of two cases. Endoscopy 1986; 18: 243-244

${ }^{4}$ Donahue DG, Saltzman JR, Krims P. Stent fracture in malignant biliary obstruction. Gastrointest Endosc 1993; 39: $864-865$

${ }^{5}$ Peck R, Wattam J. Fracture of Memotherm metallic stents in the biliary tract. Cardiovasc Intervent Radiol 2000; 23: 55-56
Corresponding Author

\section{Nageshwar Reddy, M.D.}

Asian Institute of Gastroenterology 6-3-661 Somajiguda

Hyderabad 500082

India

Fax: $\quad+91-40-2332-4255$

E-mail: aigindia@yahoo.co.in 